\title{
CONJUNTO HABITACIONAL ANA JACINTA - O PROGRAMA DE AÇÃO IMEDIATA PARA HABITAÇÃO (PAIH) EM PRESIDENTE PRUDENTE-SP
}

\author{
ANA FLÁVIA REIS JESUS ${ }^{1}$ - RENATO CARDOSO MARINHO ${ }^{1}$, MARCELA DO CARMO VIEIRA ${ }^{2}$, SIBILA \\ CORRAL DE ARÊA LEÃO HONDA ${ }^{2}$ \\ ${ }^{1}$ Discentes do curso de Arquitetura e Urbanismo da Universidade do Oeste Paulista - UNOESTE. ${ }^{2}$ \\ Docentes do curso de Arquitetura e Urbanismo da Universidade do Oeste Paulista - UNOESTE
}

\section{RESUMO}

Este artigo está embasado em pesquisa de iniciação científica elaborada no curso de Arquitetura e Urbanismo da Universidade do Oeste Paulista. Buscou-se analisar o Conjunto Habitacional Ana Jacinta, executado na região sul da malha urbana de Presidente Prudente, município do interior do Estado de São Paulo, no início da década de 1990, com financiamento do Governo Federal, por meio do Programa de Ação Imediata para Habitação (PAIH). Objetivou-se levantar questões de implantação e projetos urbano e arquitetônico desses empreendimentos na estrutura de cidades médias. A metodologia está embasada em pesquisa teórico-conceitual, documental e de campo, com mapeamentos, e relacionando todas as informações levantadas.

Palavras - chave: Expansão Urbana, Projeto Urbano, Projeto Arquitetônico, Habitação Social, Arquitetura e Urbanismo.

\section{INTRODUÇÃO}

O processo de urbanização brasileiro, historicamente, tem ocorrido de forma não controlada, com surgimento de loteamentos clandestinos e ilegais, gerando áreas periféricas sem infraestrutura e serviços urbanos, com exclusão política e social de sua população. Em contrapartida, programas de habitação social têm sido propostos pelos governos federais, desde a década de 1930, visando a construção de unidades de moradia voltadas à essa população carente.

Na gestão federal 1990-1992 (Fernando Collor de Mello), o Programa de Ação Imediata para Habitação (PAIH) foi lançado, cuja meta era de construção emergencial de unidades para reduzir (ou eliminar) o déficit habitacional brasileiro.

A cidade de Presidente Prudente, no interior do Estado de São Paulo, foi um dos municípios beneficiados por este programa (PAIH), com construção de três (3) loteamentos de habitação de interesse social, aprovados em 1990 e entregues entre 1992 e 1993. Um deles é o Conjunto Habitacional Ana Jacinta, foco desta pesquisa. Busca-se, dessa forma, contribuir com a análise da produção da moradia social, verificando questões de implantação e projeto desses empreendimentos na estrutura urbana. 


\section{METODOLOGIA}

A metodologia utilizada nesta pesquisa está baseada em aprofundamento teórico; investigação prática por meio de pesquisa documental e de campo, com análise do caso estabelecido.

\section{PROGRAMAS FEDERAIS DE HABITAÇÃO - BREVE HISTÓRICO PRÉ PLANO REAL}

O processo de urbanização no Brasil tem ocorrido de forma bastante acelerada, estimulado também pela industrialização brasileira, que atraiu grande contingente populacional para os grandes centros urbanos, resultando em forte déficit habitacional. Ao mesmo tempo, políticas públicas voltadas ao embelezamento e à instalação de infraestrutura urbana incentivaram a expulsão da população carente, direcionando-a às periferias, inclusive para áreas clandestinas. Fortes processos de segregação intra-urbana têm ocorrido nas cidades brasileiras, motivados principalmente por questões sociais e econômicas (VILLAÇA, 1999; MARQUES e TORRES, 2005; BONDUKI, 2004).

Nessa realidade, na "Era Vargas" (1930-1945), o Estado brasileiro já buscou alternativas para a redução do déficit de moradia, com a criação das Carteiras Prediais dos Institutos de Aposentadoria e Previdência em 1938, responsáveis pela construção e financiamento de unidades habitacionais nas cidades. Em 1946, no Governo do Presidente Eurico Gaspar Dutra, foi criada a Fundação da Casa Popular; e, no início da década de 1960, no Governo do Presidente Jânio Quadros, foi fundado o Instituto Brasileiro de Habitação (HONDA, 2011).

O padrão de expansão territorial urbana periférica foi consolidado, baseado na autoconstrução de moradias em terrenos clandestinos, desprovidos de infraestrutura e serviços públicos. Verifica-se também processo de verticalização urbana e de incremento nas vias de circulação de automóveis particulares (VILLAÇA, 1999; KOWARICK e BONDUKI, 1994).

Com o Regime Militar, em 1964, nova política habitacional foi aprovada, que visava a "facilitar o acesso à casa própria, por meio da construção de habitações populares e da eliminação das favelas, auxiliar a recuperação da economia e favorecer a estabilidade social" (HONDA, 2011, p.22), tendo sido criados o Sistema Financeiro de Habitação (SFH) e o Banco Nacional da Habitação (BNH). De forma geral, os locais em que conjuntos habitacionais eram executados se situavam na franja urbana ou além da malha, e sem infraestrutura ou equipamento urbanos. 
Em 1986, o BNH foi extinto, e, em 1987, foi retomada a discussão sobre reforma urbana e a questão da habitação, com inclusão de capítulo sobre política urbana na nova Constituição Federal, sancionada em 1988.

No início do Governo do Presidente Fernando Collor de Mello, em 1990, nova política habitacional foi proposta, apoiada na criação de novos programas baseados nos recursos do Fundo de Garantia por Tempo de Serviço (FGTS), como o Programa de Ação Imediata para Habitação (PAIH), que focava na construção de aproximadamente 245 mil unidades habitacionais em caráter emergencial, em prazo de 180 dias, voltadas a famílias com renda de até cinco (5) salários mínimos, por meio de execução por construtoras privadas (BOTEGA, 2007; EMILIANO, 2006; FREITAS, 2004).

Durante os anos de 1990-1991-1992, durante esse Governo, ocorreu o comprometimento dos recursos do FGTS, inclusive dos anos seguintes, que impossibilitou a liberação de novos financiamentos habitacionais, inclusive o Governo do Presidente Itamar Franco, nos anos de 1993 e 1994. No final deste último ano, com a implantação do Plano Real e a estabilização da economia do país, foi possível retomar os investimentos na área habitacional (HONDA, 2011).

\section{PRESIDENTE PRUDENTE E SEU CONTEXTO URBANO}

Presidente Prudente, cidade no oeste paulista, apresenta forte influência da produção de habitação social na sua estrutura urbana, interferindo diretamente na expansão, na periferização e na segregação socioespacial.

A base de colonização dessa cidade foi apoiada na implantação da estação ferroviária no início do século XX, inaugurada em janeiro de 1919, e em 1921, o município foi criado legalmente. Entre a década de 1920 e primeira metade da de 1950, a cidade apresentou significativa expansão territorial, sem planejamento e sem regularização legal; enquanto que o período compreendido entre a segunda metade da década de 1950 e a de 1960 ficou marcado por pequeno crescimento espacial urbano (HONDA, 2000).

Entre as décadas de 1960 e 1970, percebe-se aumento da população, ampliação do quadro industrial e desenvolvimento das atividades terciárias. Em 1968 foi iniciado o Plano Diretor de Desenvolvimento Integrado (PDDI) no município, aprovado em 1973. Vários conjuntos habitacionais foram construídos na cidade, sendo que o primeiro foi executado em 1968 (HONDA, 2011). 
A maior parte dos conjuntos habitacionais até 1982 foram implantados na região oeste da cidade. Entre os anos de 1983 e 1989, não houve aprovação de novos empreendimentos, com retomada do processo nesse último ano (MARISCO, 2003; FERNANDES, 1998).

Durante os anos de 1990 e 1992, nove conjuntos habitacionais foram aprovados e sua construção iniciada em Presidente Prudente, incluindo financiamentos do PAIH. Entre 1993 e 1996 houve aprovação de loteamentos municipais com dação em uso. A partir de 1997, mais doze empreendimentos foram construídos. A partir desses dados, verifica-se a construção de mais de 15.000 unidades habitacionais na cidade, demonstrando a importância desse tipo de empreendimento para a estrutura urbana prudentina.

O projeto do Conjunto Habitacional Ana Jacinta foi aprovado junto à Secretária de Planejamento da Prefeitura Municipal de Presidente Prudente no dia 18 de abril de 1990, segundo consta no processo de aprovação arquivado. Teve como agente financiador o Programa de Ação Imediata para Habitação (PAIH), que visava à construção de habitações para famílias com renda de até cinco salários mínimos, e é o caso analisado nesta pesquisa.

\section{CONJUNTO HABITACIONAL ANA JACINTA}

Conforme dito, o Conjunto Habitacional Ana Jacinta foi executado com financiamento do PAIH, programa habitacional do Governo Federal, lançado em 1990, na Presidência de Fernando Collor de Mello, cuja proposta seria construir aproximadamente 245 mil unidades de moradia social em 180 dias.

Tal conjunto se encontra numa região afastada a sul da malha urbana na cidade de Presidente Prudente, junto a outros empreendimentos de habitação de interesse social, alguns construídos na mesma época, o Mario Amato e o Ana Jacinta II, e outros construídos na década de 2000, o Esmeralda e o Monte Carlo. Quando de sua execução, a região de sua implantação apresentava grandes glebas (vazios urbanos), que o afastava da malha urbana consolidada; apesar de, ainda hoje, constar áreas não urbanizadas próximas ao conjunto (Figura 1).

Segundo o processo de aprovação do conjunto habitacional na Secretaria Municipal de Planejamento de Presidente Prudente, o conjunto Ana Jacinta possui 1.566 habitações unifamiliares, padronizadas, térreas; projetado apenas com lotes residenciais, além das áreas obrigatórias institucional e de lazer (Figura 2). A maioria dos terrenos, com exceção dos terrenos de esquina, possui $8,5 \mathrm{~m}$ de testada por $19 \mathrm{~m}$ de profundidade, totalizando $161,5 \mathrm{~m}^{2}$. A área 
construída de cada unidade é de aproximadamente $29 \mathrm{~m}^{2}$, constituído de uma sala-cozinha, um quarto e um banheiro (Figura 3).

Segundo levantamento in loco, dez anos após a entrega das unidades, há bastante alteração em relação ao uso e ocupação do bairro. Surgiram muitas lojas, igrejas, estabelecimentos de lazer e serviços no que antes eram lotes residenciais (Figura 4).

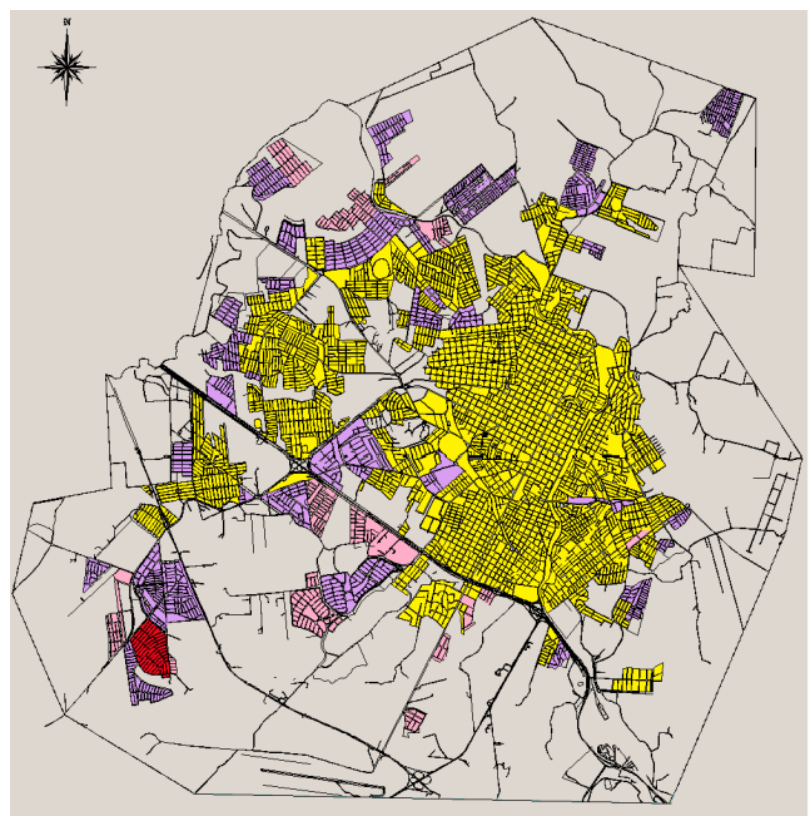

LEGENDA:

CONJUNTO HABITACIONAL ANA JACINTA

MALHA URBANA DE PRESIDENTE PRUDENTE EM 1990

LOTEAMENTOS IMPLANTADOS ENTRE 1990-1999

LOTEAMENTOS IMPLANTADOS ENTRE 2000-2009

Figura 1. Malha urbana de Presidente Prudente e localização do Ana Jacinta (Fonte: autores, 2013).

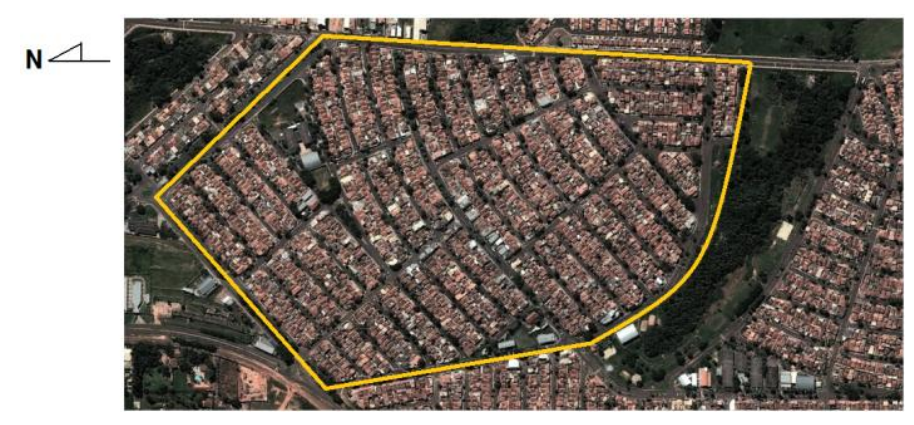

Figura 2. Imagem aérea do Conjunto Habitacional Ana Jacinta (Fonte: Google Earth, maio 2013)

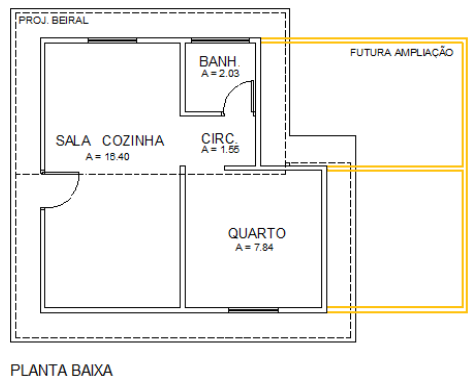

Figura 3. Planta baixa esquemática (Fonte: Prefeitura Municipal de Presidente Prudente) 


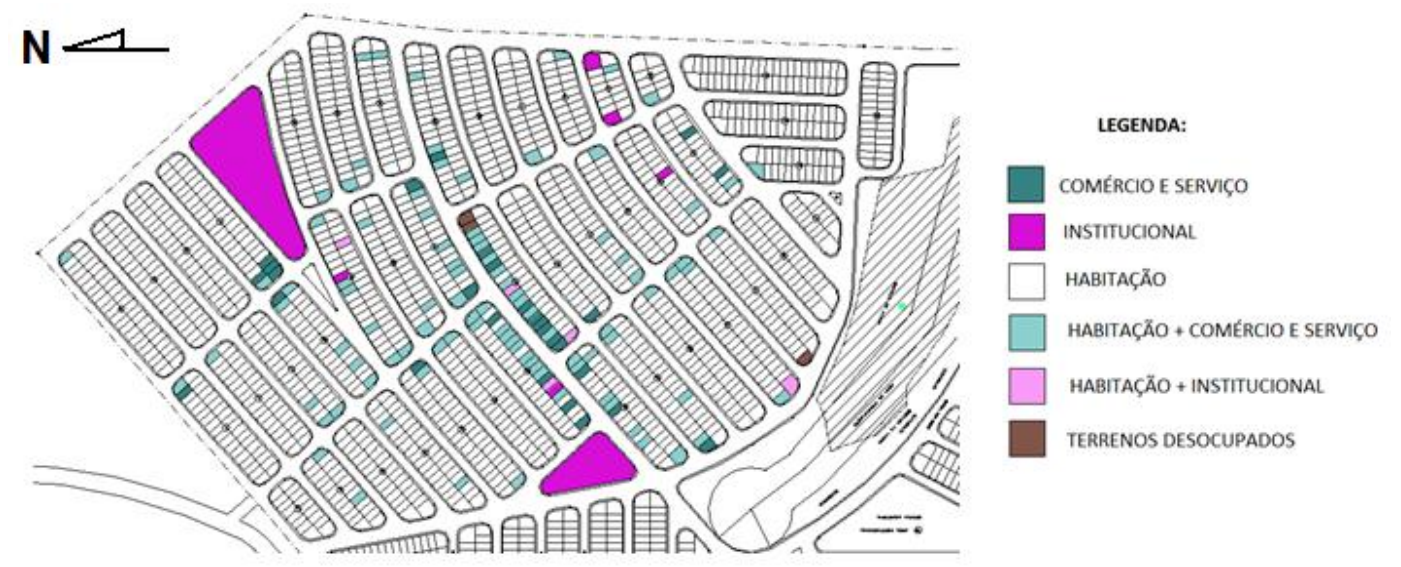

Figura 4. Planta de uso do solo no Ana Jacinta em 2013 (Fonte: autores, 2013).

Poucas são as casas que permanecem como foram entregues pela Prefeitura em 1993 (Figura 5), conforme pode ser observado na planta (Figura 6) do levantamento sobre a manutenção e alteração das unidades. Na maioria dos casos, o lote abriga estabelecimento comercial ou de serviço e uma residência (Figura 7). A concentração desses estabelecimentos em uma determinada área do bairro fez surgir um pequeno centro comercial local.

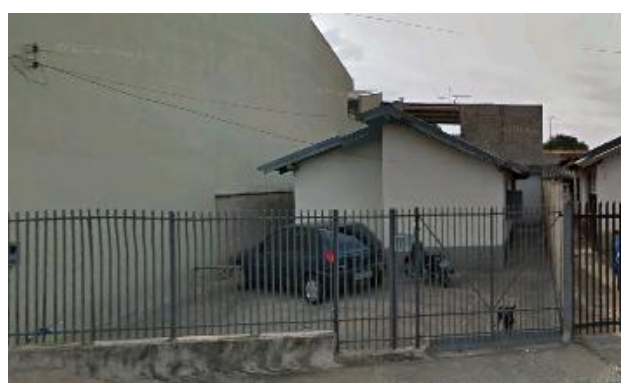

Figura 5. Residência original no Conjunto Ana Jacinta (Fonte: autores, 2013)

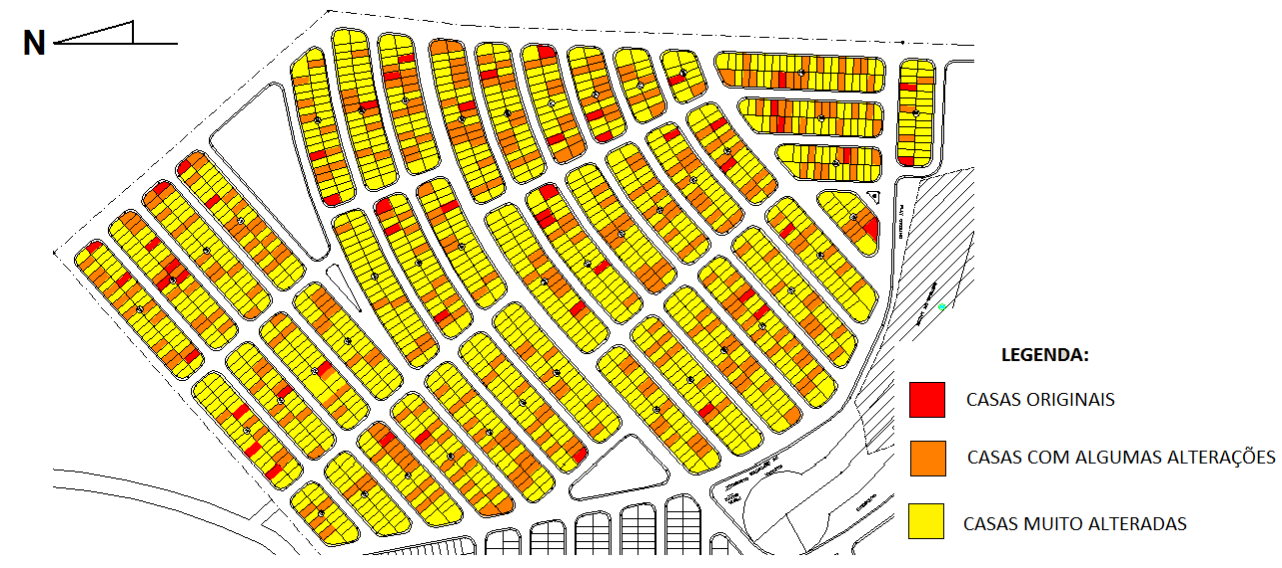

Figura 6. Planta com as residências alteradas (Fonte: autores, 2013) 


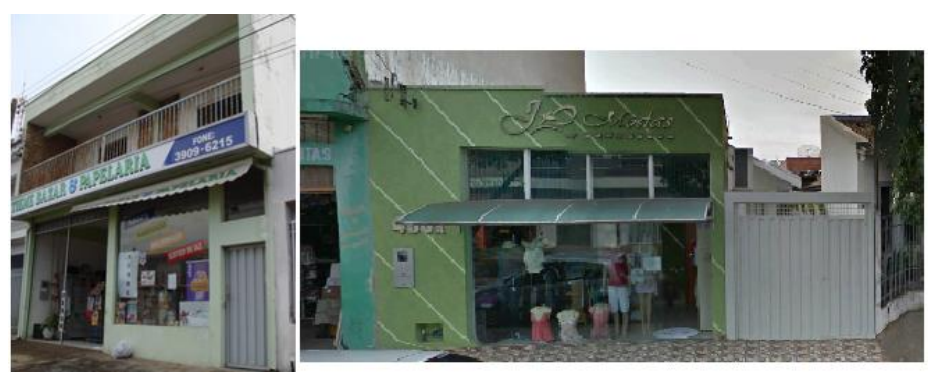

Figura 7. Comércio e residência dividindo o mesmo lote (Fonte: autores, 2013)

Algumas das unidades habitacionais ainda conservam a estrutura original, com adição de alguns cômodos, de edícula ou mesmo de uma varanda. Porém a grande maioria das casas sofreu grandes mudanças, sendo impossível enxergar qualquer semelhança com as casas originais do conjunto Ana Jacinta. Muitas reformas ainda estão acontecendo no bairro, e muitas vezes desacompanhadas de um profissional habilitado, sem levar em conta a lei de zoneamento do local, e sem registro junto à Secretaria de Planejamento.

Por meio de levantamento realizado no bairro, nota-se que a grande maioria das casas permanecem térreas. As edificações de dois pavimentos estão distribuídas pelo bairro, e geralmente abrigam algum estabelecimento comercial no primeiro pavimento e a residência no segundo. As poucas edificações de três pavimentos existentes estão concentradas na área comercial do bairro, com o primeiro pavimento como comércio e os outros dois para residência (Figura 8). Porém, segundo a lei de zoneamento da cidade, o Conjunto Habitacional Ana Jacinta pertence a ZR4, que estipula o gabarito de altura máxima em dois pavimentos.

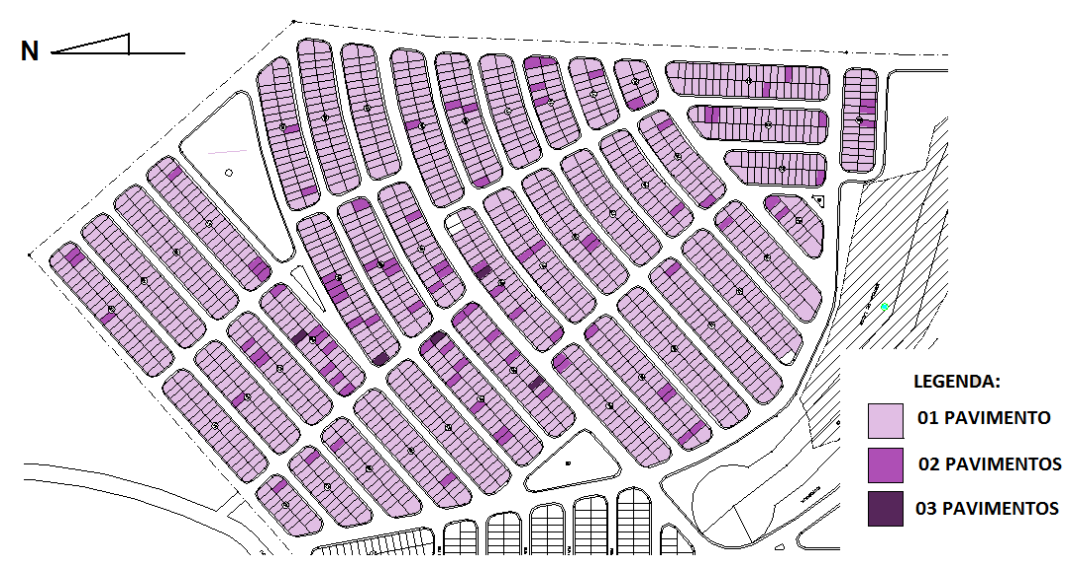

Figura 8. Planta de gabarito de altura (Fonte: autores, 2013)

A partir desses levantamentos, é possível perceber a grande modificação arquitetônica e urbanística que tem ocorrido no conjunto habitacional analisado. Parte desse processo é bastante comum, cujos moradores buscam adequações e melhoras nas suas unidades, diferenciando-as das 
demais. Assim como pode ser assumido que alguns moradores não são os beneficiados originais, afinal é realidade verificada em todos os empreendimentos de habitação social no país.

No entanto, também podem ser verificadas alterações estimuladas pela grande distância do loteamento com a malha urbana consolidada e com áreas comerciais, resultando em surgimento de centralidade urbana, com comércios e serviços locais, voltados aos moradores desse conjunto habitacional e dos circunvizinhos.

\section{CONSIDERAÇÕES FINAIS}

A partir desta pesquisa, pode-se observar aspectos de conjunto habitacional executado no início da década de 1990, com financiamento federal por meio do Programa de Ação Imediata para Habitação (PAIH). Tal empreendimento, conjunto Ana Jacinta, executado em Presidente Prudente-SP, foi implantado em gleba fora da malha urbana consolidada, e, vinte anos após sua entrega (1993-2003), sua população ainda encontra-se prejudicada pela distância de áreas de comércios e serviços urbanos.

A concentração de unidades de moradia social resulta em homogeneidade urbana, negativa para os padrões do urbanismo pós-moderno, que poderia ser identificado como elemento segregador intra-urbano, aprofundamento desta pesquisa que se buscará analisar. As alterações urbanísticas, entretanto, refletem interesse de sua população com o local, melhorando e investindo nas unidades e bairros que compõem a região urbana.

Ou seja, o descaso político em excluir uma população carente para locais fora da estrutura urbana, em unidades de moradia bastante reduzidas (pequenas), com uma extensão do loteamento bastante grande, fora dos padrões aceitáveis nos dias atuais (1.566 unidades), não gerou, no entanto, reflexos socioespaciais negativos no bairro estudado, proporcionando aspectos de centralidade e afeição ao novo espaço urbano criado.

\section{REFERÊNCIAS}

BONDUKI, N. Origens da habitação social no Brasil: arquitetura moderna, lei do inquilinato e difusão da casa própria. 2a .ed. São Paulo: Estação Liberdade, 2004.

BOTEGA, L.R. De Vargas a Collor: urbanização e política habitacional no Brasil. Espaço Plural, ano VIII, $\quad$ o..17, 20.semestre 2007, p.65-72. Disponível em: http://erevista.unioeste.br/index.php/espacoplural/article/view/1619/1308. Acesso em: 30.mar.2010. 
EMILIANO, E.O. Legislação para Habitação de Interesse Social - estudo de caso do município de Campinas. 2006. Dissertação (Mestrado em Urbanismo) - Centro de Ciências Exatas, Ambientais e de Tecnologias, Pontifícia Universidade Católica, Campinas.

FERNANDES, S.A.S. Territorialização das políticas habitacionais em Bauru e Presidente Prudente. 1998. Dissertação (Mestrado em Geografia) - Faculdade de Ciências e Tecnologia, Universidade Estadual Paulista, Presidente Prudente.

FREITAS, E.L.H. Como qualificar conjuntos habitacionais populares. Brasília: Caixa Econômica Federal, 2004.

HONDA, S.C.A.L. A centralidade urbana em Presidente Prudente. 2000. Dissertação (Mestrado em Arquitetura e Urbanismo) - Faculdade de Arquitetura e Urbanismo, Universidade Presbiteriana Mackenzie, São Paulo.

HONDA, S.C.A.L. Habitação de Baixa Renda como Produto do Capital - o Programa de Arrendamento Residencial (PAR) em Presidente Prudente-SP. 2011. Tese (Doutorado em Arquitetura e Urbanismo) - Faculdade de Arquitetura e Urbanismo, Universidade Presbiteriana Mackenzie, São Paulo.

KOWARICK, L.; BONDUKI, N. Espaço urbano e espaço político: do populismo à redemocratização. In: KOWARICK, L. (org.). As lutas sociais e a cidade: São Paulo - passado e presente. 2a.ed.rev. São Paulo: Ed. Paz e Terra, 1994. p.147-177.

MARISCO, L.M.O. A norma e o fato: abordagem analítica da segregação sócio-espacial e exclusão social a partir dos instrumentos urbanísticos. 2003. Tese (Doutorado em Geografia) - - Faculdade de Ciências e Tecnologia, Universidade Estadual Paulista, Presidente Prudente.

MARQUES, E.; TORRES, H. (org). São Paulo: Segregação, Pobreza e Desigualdades Sociais. São Paulo: Editora SENAC São Paulo, 2005.

VILLAÇA, F. Uma contribuição para a história do planejamento urbano no Brasil. In: DÉAK, C; SCHIFFER, S.R (orgs). O Processo de Urbanização no Brasil. São Paulo, EDUSP, 1999, p.169-243. 